\title{
The Relationship Between Self-Efficacy and Achievement Motivation in Adolescents: A Moderated Mediating Model of Self-Identity and Hope
}

\author{
Liqin Liu, Lesen Cheng* \\ Department of Psychology, Weifang Medical University, Weifang, China \\ Email address: \\ lq10103angela@163.com (Liqin Liu), lesencheng@sina.com (Lesen Cheng) \\ ${ }^{*}$ Corresponding author
}

\section{To cite this article:}

Liqin Liu, Lesen Cheng. The Relationship Between Self-Efficacy and Achievement Motivation in Adolescents: A Moderated Mediating Model of Self-Identity and Hope. Psychology and Behavioral Sciences. Vol. 7, No. 3, 2018, pp. 69-76. doi: 10.11648/j.pbs.20180703.15

Received: August 12, 2018; Accepted: August 29, 2018; Published: October 13, 2018

\begin{abstract}
Background: Adolescents were the critical period of physical and mental development, in terms of positive psychology, some internal psychological factors may accelerate the development, given the importance of achievement motivation--the essence of development for adolescents in school and span of life, it may be the key variables to change the trace of the growth, combined with other factors, such as self-efficacy, self-identity, many researchers had explored the association each other, but few authors tested the interaction mechanism of them, especially, hope, the core factor of positive psychology, may be the another variable to affect the mentioned relationship. It was urged to find the interaction mechanism. Objective: The study examined the relation of self-efficacy and achievement motivation, more precisely, the current research estimated mediated effect of self-identity and the moderated effect of hope in the relationship between self-efficacy and achievement motivation. Methods: To fulfil the goal, 473 adolescents participated in the investigation by completing multiple scales in China and diverse analysis methods were used to deal the data. Results: The results showed that self-efficacy significantly linked with achievement motivation, and the self-identity partially mediated the relation between self-efficacy and achievement motivation in adolescents, and the hope moderated the mediating paths. Conclusion: From what mention above, the self-identity and hope, the mediating role and moderator, respectively, were the underlying mechanism of the relationship between self-efficacy and achievement motivation. The strengths and weaknesses based on the study were discussed.
\end{abstract}

Keywords: Self-Efficacy, Self-Identity, Achievement Motivation, Hope, Adolescents, Moderated Mediating Model

\section{Introduction}

Achievement motivation was a crucial factor that affected the adolescents' performance in school, which can determine the academic success, learning behavior and future goal orientations [1-2], for one thing, it linked with the confidence, persistence facing to challenges, learning ways whether selected sharing with peers [3] and performance expectations [4-5], for another thing, it negatively associated with anxiety and depression [6-7], because adolescents spent most their time studying in school learning, the academic success and school satisfaction were essential, which may be influenced by achievement motivation of adolescents, it was more likely affected academic performance and integration [8], so some researchers payed close attention to it.
With the rising and development of positive psychology, the impact of hope and self-efficacy on achievement goal increasingly, academic adjustment and well-being caught scholars' attention [9-10], the two concepts were core components in positive psychology, those who only believed themselves in doing something successfully and had the ability to succeed can possess higher achievement motivation, that was said, positive traits were key to achievement motivation. Self-identity was the central idea in personality development theory of Erikson, the different stage for personality, the different standard of self, it was more possible to experience achievement motivation, emotion, goal orientation and school satisfaction, more importantly, emotion, goal orientation and satisfaction can be regarded as the part of hope and self-efficacy [11-12]. Given the 
importance of hope, self-efficacy and self-identity to achievement motivation and the unclear relation among them, the current study aimed to demonstrated the underlying mechanism among these variables.

\subsection{Achievement Motivation}

Achievement motivation referred to three different needs that developed with time [13-14], different stage of personality, adolescents experienced distinct level of it [15], this three needs were:(1) a need to achieve; (2)a need to affiliate; (3)a need to power [16]. More precisely, achievement motivation prominently related to academic performance, goal orientation, learning behavior, subjective well-being and school satisfaction [17-18], the characteristics can be considered as the positive structures in personality, from this, achievement motivation held the values to be study because of the direct and indirect link with adolescents' future success and persistence to difficult school tasks [19], in term of physical changes and maturation, adolescents were in a rapid growth stage, achievement motivation may directly and indirectly affected their every aspects across physical and mental health. It was worthy to designed the study for adolescents.

\subsection{Self-Efficacy, Hope, Self-Identity and Achievement Motivation}

\subsubsection{Self-Efficacy and Achievement Motivation}

Self-efficacy, known as a ability that utilized to describe how to behave and possess the skills to do something, which determined whether to conduct a behavior or not [20] as well as the degree of efforts to accomplish tasks [21]. Self-efficacy had consistently demonstrated to predict the achievement motivation [22-24], particularly, it was linked with academic and work-related achievement [25-26], in other words, it was related with some positive factors and can be argued a critical component of positive behavior [27].

Much of researches had indicated that self-efficacy influenced the students' motivation, achievement, choice, interest, effort degree and persistence of confronting obstacles [28-30], individuals with a strong self-efficacy were willing to opt to challenging tasks instead of avoiding future failure and remained their efforts for the goal even though the possible setbacks and easily recovered themselves as soon as they can after they experienced the frustrations [31], from this, we draw the conclusions that the effect of self-efficacy on achievement motivation needed to be further confirmed by current study because of the importance of the education implications.

\subsubsection{Hope and Achievement Motivation}

Hope was considered as another efficacy, similar with self-efficacy, zhou and Snyder argued that they were two analogous conceptual and operational elements[32]. according to the Hope Theory of Snyder in 2002, hope was referred to a cognitive factor including 2 dimensions, the pathways-thinking and agency-thinking, the former was the paths of expecting goals, the latter was the motivation to attain the goals [33-34], it highlighted the goal-pursuing elements [35], as the positive psychological traits, hope also was the dynamics and power in adolescents, it may help individuals to adjust emotion facing to setbacks and sustained efforts for the successful goals pursuing [36].

Ling,etal found that students with high level of hope manifested high optimism, life satisfaction and self-esteem , individuals with higher level of hope tended to perform well in possessing efficacy to approach goals and got positive feedback, such as encourage and praise, as well as experience more positive emotion, low depression [37-38] and reduce future psychological problems [39]. as a internal dynamic structure to reach goal, the concept was similar with achievement motivation, given the aspect, our study aimed to consider the hope as a moderated variables to explore the effect on the relation of self-efficacy and achievement motivation, few researchers referred to the scope, our attempt will increase the empirical theory to the gap.

\subsubsection{Self-Identity and Achievement Motivation}

Self-identity was the core component of personality development, erikson argued that it was the choice and think about the great questions of self-development and self-acknowledgement, such as career, dream, view of life, view of values [59]. adolescents were in the key development period to acquire self-identity, some literatures had consistently found that identity associated with passive behaviors, such as academic procrastination and burnout [40], which may result in bad academic performance and decreased the confidence, school satisfaction and increased the danger of anxiety and depression, all of above mentioned may impair the achievement motivation as our assumption, owing to few literatures describing the effect of identity to achievement motivation, our study hoped to find magical effect on the relationship between self-efficacy and achievement motivation.

\subsection{The Current Study}

From mentioned above, we can find that few articles explore the effects of self-identity and hope to the relation between self-efficacy and achievement motivation, in order to compensate for the pity, the paper aims to find the underlying mechanism of self-identity and hope to achievement motivation, in other words, we will estimate two assumptions, one is that the mediated effect of self-identity, another one is the moderated effect of hope in the mediating model. And the study further verifies the link between self-efficacy and achievement based on the author's previous study [23].

\section{Methods}

\subsection{Participants}

Multiple anonymous, self-reported questionnaires were carried out for the samples of 500 Chinese adolescents in the city of Zhengzhou in Henan province by convenience 
sampling, 18 samples were ruled out owing to the invalid self-report, in total 473 samples, of which, 263 females and 210 males (juvenile:239, youth:234; urban:266, rural:207; middle school:195, high school:278), who were not reluctant to join in the investigation and gave their true reaction to the contents taking on the four questionnaires within approximately 20-30 minutes. after accomplishing, every participators got a pen as the gift of our thanks.

\subsection{Measures}

\subsubsection{Self-Identity}

We utilized the Chinese version of Self-identity scale to measure adolescents' development [41], the coefficient of internal consistency was 0.73 , which consists of 19 items with a 4-Likert scale, ranging from 1 (not at all like me) to 4 (very like me), the reliability and validity were accepted in Chinese culture background. The present research, the total Cronbach' $\alpha$ was 0.74 .

\subsubsection{Self-Efficacy}

Adolescents rated their self-efficacy based on 10 items with a 4-Likert scale ranging from 1 (strongly disagree) to 4 (strongly agree) in the Chinese version of self-efficacy scale [42], the coefficient of internal consistency was 0.87 , the higher scores, the higher confidence for personality, in this study, the Cronbach' $\alpha$ was 0.78 .

\subsubsection{Hope}

Hope was measured using Chinese version of Dispositional Hope Scale [43], which consists of 12 items with a 8-Likert scale ranging from 1 (not at all right) to 8 (very right), of which, 4 items were used to transfer participants' attention that were not calculated the total scores, the remained 8 items included 2 dimensions: pathways-thinking and agency-thinking, their Cronbach' $\alpha$ were 0.73 and 0.75 , respectively, the total Cronbach' $\alpha$ was 0.78 . In the study, the Cronbach' $\alpha$ of 2 dimensions were 0.73 and 0.77 and the total of that was 0.72 .

\subsubsection{Achievement Motivation}

Achievement motivation was measured by Chinese version of Achievement motivation scale [6], which consists of 30 items including 2 dimensions, named motivation to pursue success (Ms) and motivation to avoid failure (Maf), participants responded from 1 (not at all suit to me)to 4 (very fit me), the total scores was Ma=Ms-Maf. In this study, the Cronbach' $\alpha$ of 2 dimensions were 0.85 and 0.87 and the total of that was 0.76 .

\subsection{Data Analysis}

All data processing used SPSS version 22.0 and Amos 24.0 version program to realize our goal and the maximum likelihood method was used to handle missing data [44]. To avoid multicollinearity, we carried out data centralization processing. First, descriptive statistics and Pearson correlation analysis were performed to estimate the relation among all variables. Second, structural equation model was used to evaluate the mediated effect of self-identity on the relation between self-efficacy and achievement motivation, mediation effects were certified by bootstrapping method with 1000 samples, and computed the percentile confidence intervals and bias-corrected confidence intervals, but, this research, we applied the percentile confidence intervals as confirmed standard (CI). Third, the hierarchical regression analysis was carried out to test the moderated effect of hope on the mediating model.

\section{Results}

\subsection{Descriptive and Correlation Analysis}

The distribution of the data was not non-normality. Univariate skewness of 2.0 and higher and kurtosis of 7.0 and higher is appropriate to high non-normality and easily contributed to problems during data analysis [45-46]. In this study, all values of variables about that were below these levels, the data were well. The mean value and standard error were also took on the below table (seeing Table 1). The relation coefficients among all variables were remarkable $(p<0.01)$, and it was negative notably linked that motivation to avoid failure and other variables (seeing Table 1).

Table 1. Descriptive statistics and correlation among all variables.

\begin{tabular}{|c|c|c|c|c|c|c|}
\hline & 1 & 2 & 3 & 4 & 5 & 6 \\
\hline 1 self-identity & 1 & & & & & \\
\hline 2 self-efficacy & $0.38^{* *}$ & 1 & & & & \\
\hline 3 hope & $0.42^{* *}$ & $0.56^{* *}$ & 1 & & & \\
\hline 5 motivation to avoid failure & $-0.40^{* *}$ & $-0.20^{* *}$ & $-0.23^{* *}$ & $-0.26^{* *}$ & 1 & \\
\hline 6 achievement motivation & $0.46^{* *}$ & $0.42^{* *}$ & $0.47^{* *}$ & $0.76^{* *}$ & $-0.82^{* *}$ & 1 \\
\hline M & 54.85 & 27.93 & 42.16 & 41.35 & 36.16 & 5.19 \\
\hline Skew & 0.03 & 0.20 & -0.29 & 0.09 & -0.28 & 0.48 \\
\hline Kurt & -0.33 & 0.86 & 0.06 & 0.13 & 0.20 & 0.93 \\
\hline
\end{tabular}

Note: ${ }^{* *} p<0.01$

\subsection{The Mediating Effect of Self-Identity}

To further explore whether the mediated model was trustworthy or not, the article estimated the mediating effect using structural equation model by controlling the age, gender and grade and affirmed the effect with bootstrapping method for 1000 
bootstrap samples and computed 95\%confident intervals providing in Table 3 and Figure 1. The mediating model goodness of fit index were took on Table 2, from this, we can concluded that the mediated model was very good and can be accepted.

Table 2. The goodness of fit index for the mediated model.

\begin{tabular}{|c|c|c|c|c|c|c|c|c|c|}
\hline Index & $\mathrm{X}^{2} / \mathrm{DF}$ & GFI & AGFI & NFI & RFI & PNFI & PCFI & RMR & RMSEA \\
\hline value & 0.840 & 0.995 & 0.988 & 0.987 & 0.976 & 0.526 & 0.533 & 0.010 & 0.000 \\
\hline
\end{tabular}

The mediating effect of self-identity in the relationship between self-efficacy and achievement motivation was significant (indirect effect: $\mathrm{B}=0.315, \mathrm{p}<0.05$; total effect: $\mathrm{B}=0.415, \mathrm{p}<0.05$; direct effect: $\mathrm{B}=0.280, \mathrm{p}<0.05$ ), the self-efficacy significantly predicted self-identity $(B=0.381, p<0.05)$, the self-identity significantly predicted achievement motivation $(B=0.354, p<0.05)$. The all $95 \%$ confident intervals excluded zero of indirect effect from 0.091 to 0.182 , of direct effect from 0.190 to 0.378 , of total effect from 0.314 to 0.527 (seeing Table 3), the proportion of explanation for indirect effect was $0.315 / 0.415 * 100 \%=75.90 \%$, the result coming from structural equation model was rigorous, in other words, the self-identity played particial mediated role on self-efficacy and achievement motivation.

Table 3. The mediating effects report by bootstrapping test.

\begin{tabular}{|c|c|c|c|c|c|c|c|}
\hline \multirow{3}{*}{ variables } & \multirow{3}{*}{ Point estimate } & \multirow{2}{*}{\multicolumn{2}{|c|}{ Product of coefficients }} & \multicolumn{4}{|c|}{ Bootstrapping } \\
\hline & & & & \multicolumn{2}{|c|}{ Bias-Corrected $95 \%$ CI } & \multicolumn{2}{|c|}{ Percentile $95 \%$ CI } \\
\hline & & SE & $\mathbf{Z}$ & Lower & Upper & Lower & Upper \\
\hline Total Effects & & & & & & & \\
\hline $\begin{array}{l}\mathrm{Ma}<- \text { SE } \\
\text { Indirect Effects }\end{array}$ & 0.415 & 0.055 & $7.55^{*}$ & 0.314 & 0.527 & 0.314 & 0.527 \\
\hline $\begin{array}{l}\mathrm{Ma}<- \text {-SE } \\
\text { Direct Effects }\end{array}$ & 0.135 & 0.024 & $5.63^{*}$ & 0.093 & 0.185 & 0.091 & 0.182 \\
\hline $\begin{array}{l}\text { Ma<--SE } \\
\text { Total Effects }\end{array}$ & 0.280 & 0.049 & $5.71^{*}$ & 0.190 & 0.378 & 0.190 & 0.378 \\
\hline $\begin{array}{l}\mathrm{SI}<--\mathrm{SE} \\
\text { Indirect Effects }\end{array}$ & 0.381 & 0.053 & $7.19^{*}$ & 0.278 & 0.484 & 0.280 & 0.485 \\
\hline $\begin{array}{l}\text { SI<--SE } \\
\text { Direct Effects }\end{array}$ & - & - & - & - & - & - & - \\
\hline $\mathrm{SI}<-$-SE & 0.381 & 0.053 & $7.19^{*}$ & 0.278 & 0.484 & 0.280 & 0.485 \\
\hline
\end{tabular}

Note. 1,000 bootstrap samples ${ }^{*} \mathrm{p}<0.05$

$\mathrm{SE}=$ Self-efficacy, sI=Self-identity, ma=achievement motivation

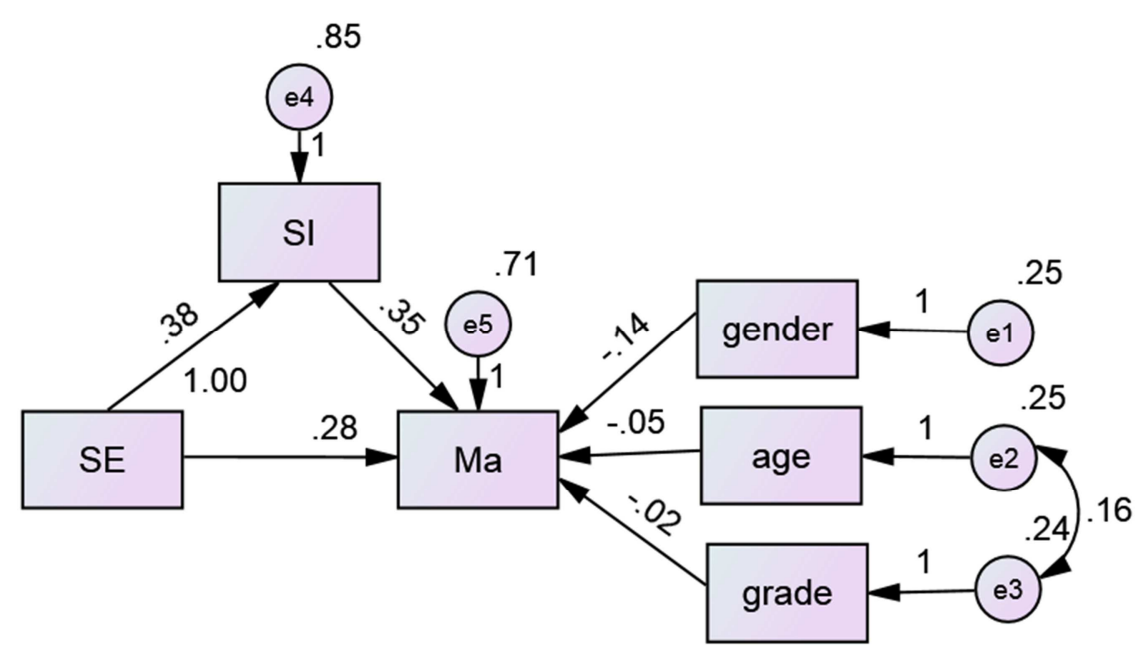

Note: $\mathrm{SE}=$ self-efficacy, SI=self-identity, Ma=achievement motivation, $\mathrm{CI}=95 \%$, Bootstrap sample $=1000$

Figure 1. The mediated role of self-identity in the relationship between self-efficacy and achievement motivation.

\subsection{The Moderating Effect of Hope}

Hierarchical regression analysis was conducted to evaluate whether the hope moderated the association of self-efficacy and achievement motivation in the mediating process or not. The results showed that hope played a distinct role in the mediating model. To further perform the process, we tested two interaction effects, respectively. They were: (1) the interaction between hope and self-efficacy on achievement motivation. (2) the interaction between hope and self-identity on achievement motivation. and during the process, the gender, age and grade were controlled in older to avoid some influences, which created three models, the results of the compared models were below (seeing Table 4). 
From the Table, we can draw the conclusions that: (1)Gender, age and grade didn't play the role of controlled effects (gender: $\beta=-0.09$; age: $\beta=-0.03$; grade: $\beta=0.01$, all $p>0.05)$, the model 1 was not significant $(\Delta F=1.20, \mathrm{p}>0.05)$. (2) The model 2 was significant $(\Delta F=74.12, \mathrm{p}<0.001)$, self-identity, self-efficacy and hope predicted the achievement motivation $\quad(\mathrm{SI}: \beta=0.029, \quad \mathrm{p}<0.001 ; \quad \mathrm{SE}: \beta=0.16, \quad \mathrm{p}<0.01$; Hope: $\beta=0.26, \quad p<0.001)$. (3)The model 3 was significant $(\Delta F=3.38, \mathrm{p}<0.05)$, the interaction between self-efficacy and hope was not remarkable $(\beta=-0.02, p>0.05)$, the interaction between self-identity and hope was notable $(\beta=0.98, p<0.05)$.

Table 4. Hierarchical regression analysis for the moderator of hope in the mediated model.

\begin{tabular}{|c|c|c|c|c|c|c|c|c|}
\hline Model & Independent & Dependent & $\mathrm{B}$ & SE & $\beta$ & $\mathbf{R}^{2}$ & $\Delta \mathbf{R}^{2}$ & $\Delta \mathbf{F}$ \\
\hline \multirow{3}{*}{1} & gender & & -0.17 & 0.09 & -0.09 & \multirow{3}{*}{0.01} & \multirow{3}{*}{0.01} & \multirow{3}{*}{1.20} \\
\hline & age & Achievement Motivation & -0.06 & 0.12 & -0.03 & & & \\
\hline & grade & & 0.02 & 0.13 & 0.01 & & & \\
\hline \multirow{5}{*}{2} & gender & \multirow{5}{*}{ Achievement Motivation } & -0.09 & 0.08 & -0.04 & \multirow{5}{*}{0.33} & \multirow{5}{*}{0.32} & \multirow{5}{*}{$74.12^{* * *}$} \\
\hline & age & & -0.04 & 0.10 & -0.02 & & & \\
\hline & grade & & -0.03 & 0.10 & -0.01 & & & \\
\hline & Self-identity & & 0.29 & 0.04 & $0.29^{* * *}$ & & & \\
\hline & hope & & 0.26 & 0.05 & $0.26^{* * *}$ & & & \\
\hline \multirow{7}{*}{3} & gender & \multirow{7}{*}{ Achievement Motivation } & -0.09 & 0.08 & -0.05 & \multirow{7}{*}{0.34} & \multirow{7}{*}{0.01} & \multirow{7}{*}{$3.38^{*}$} \\
\hline & age & & -0.04 & 0.10 & -0.02 & & & \\
\hline & grade & & -0.04 & 0.10 & -0.02 & & & \\
\hline & Self-identity & & -0.12 & 0.18 & -0.12 & & & \\
\hline & Self-efficacy & & 0.17 & 0.16 & 0.17 & & & \\
\hline & hope & & -0.45 & 0.29 & -0.45 & & & \\
\hline & SI*HOPE & & 0.98 & 0.43 & $0.98^{*}$ & & & \\
\hline
\end{tabular}

Note: ${ }^{*} \mathrm{p}<0.05,{ }^{* *} \mathrm{p}<0.01,{ }^{* * *} \mathrm{p}<0.001, \mathrm{sE}=$ Self-efficacy, $\mathrm{sI}=$ Self-identity

\section{Discussion}

The association between self-efficacy and achievement motivation had increasingly attracted people's attentions recent years and supported by some theoretical and empirical researches $[23,47]$, but the underlying mechanism of them remained unclear, the study explored the unanswered moderated mediating effects of self-identity and hope though the association between achievement motivation and themselves, respectively. In other words, self-identity and hope linked with achievement motivation respectively [48-49], but the mixed model of moderated mediating effects deserves us to further evaluate, the study completed the task, the results indicated that: (1) we further verified the relation between self-efficacy and achievement motivation, the independent variable can account for $41.5 \%$ variations for dependent variable. (2) the self-identity partially mediated the relation between self-efficacy and achievement motivation, which accorded to the previous research [23]. (3) the moderated effect of hope was manifested in the mediating model, which only occurred the interaction effect between self-identity and hope.

As the result of mediating effect, adolescents experienced higher self-efficacy, developed higher self-identity, feel greater academic success and higher level of psychological adjustment [50], more willing to immerse themselves into the school tasks or academic performance and increased the positive school emotion [51-52], all of which together enhanced the achievement motivation, with the promotion of achievement motivation, which may in turn increased the self-efficacy and self-identity with emergence of academic satisfaction [53] and consciously performed better at school
[51] and demonstrated more emotion stability [54] for adolescents. From all above, school educators should take the self-identity into account aiming at cultivating the achievement motivation, only when the adolescents highly approval them can they develop higher achievement motivation.

As the consequence, hope moderated the mediating model, it acted as the critically internal powerful factor contributing to the variations for the relation on self-efficacy and achievement motivation. On the one hand, hope moderated the direct effect of the association on self-efficacy and achievement motivation, which converted the path coefficients and the significance, the powerful factor of hope may maximized the likelihood of optimistic cognition, the way to thinking [55] and goal orientations [56], so the hope exerted the moderating effect to the path. On the other hand, the interaction between hope and self-identity explained the variations of independent variable to dependent variable, it was more likely that hope weakened the passive attitude for themselves of adolescents, under the conditions of higher level of hope, the higher of achievement motivation of them with higher self-identity, in other words, achievement motivation changed ranging from level of low hope to level of high hope, different level had a discrepant influence of the mediating model, also, hope altered the degree of the relation between self-efficacy and achievement motivation by the path of interaction of hope and self-identity. Those who had the higher level of hope may expressed themselves more positively and developed the proper strategies to cope with anxiety in school [57], which in turn improved the development of self-identity, and adolescents with higher hope may expected success for future, so the higher 
achievement motivation [58].

\subsection{Weaknesses}

First, self-identity continues development for adolescents until completing being shaped at 20 ages and affected by social effects, so the scale can't test it perfectly, and the scale of hope were little difficult for secondary school students because the limitations of understanding ability. Second, sampling bias may lead to potential errors for results. Furthermore, a large samples and stratified random sampling should be put in practice so that increase the quality of investigation in the future. Basing on the weaknesses, the study should adopt oral explanation of every item for adolescents who can't understand the description to enhance the reliability and validity of the study.

\subsection{Strengths}

Despite given the weaknesses, the current research had its practical value for the direction of adolescents' development. The literature realized the goal based on positive psychology, and explored the underlying mechanism by leading in hope, which was failed to be found. It suggested that parents and educators should make efforts to fostered the higher self-identity of adolescents and improved their level of hope so that enhanced the wish to pursue success with the higher achievement motivation. all in all, the paper suggested that all factors should be heightened in daily study and family life, in other words, parents and teachers praised and encouraged adolescents more, and found the shining point of every students instead of chastising them, teachers and parents should took different measures to adolescents and be patient to the process just as the movie of The Chorus, particularly in China.

\section{Conclusion}

The article explored the underlying mechanism of self-identity and hope accounting for the relation of self-efficacy on achievement motivation, the results manifested that self-identity partially mediated the relation between self-efficacy and achievement motivation, the hope as a inside powerful factor affected the mediated model, increasing the link of independent variable and dependent variable, it played the role of moderator. The findings indicated that there were some variables exerting diverse effects on the association between self-efficacy and achievement motivation, which was underlying mechanism being used to direct adolescents' growing.

\section{Funding}

The research was not supported by any funding.

\section{Acknowledgements}

We thanked all adolescents in Zhengzhou, the capital city of
Henan province for participating the investigation.

\section{References}

[1] Ames, C. (1992). Classrooms: Goals, structures, and student motivation. Journal of Educational Psychology, 84 (3), 261271 .

[2] Cho, Y., Weinstein, C., \& Wicker, F. (2011). Perceived competence and autonomy as moderators of the effects of achievement goal orientations. Educational Psychology: An International Journal of Experimental Educational Psychology, 31 (4), 393-411.

[3] Caprara, g. V., Fida, r., vecchione, M., del Bove, g., vecchio, G. M.,\& Barbaranelli, c., et al. (2008). Longitudinal analysis of the role of perceived self-efficacy for self-regulated learning in academic continuance and achievement. Journal of Educational Psychology, 100, 525-534.

[4] Kosheleva, E. Y., Amarnor, A. J., \& Chernobilsky, E. (2015). Stress factors among international and domestic students in Russia. Procedia Social and Behavioral Sciences, 200, 460 466.

[5] Misra, R.,\& Castillo , 1. G. (2004). Academic stress among college students: Comparison of American and international students. International Journal of Stress Management, 11, 132-148.

[6] Ye, R., Hegtvet , k. A. (1989). The relationships of achievement motivation test, anxiety intelligence and performance among high school students. Chinese Journal of Applied psychology, 4 (3), 52-56.

[7] American Psychiatric Association \& DSM-5 Task Force. (2013). Diagnostic and statistical manual of mental disorders: DSM-5. Arlington, VA: American Psychiatricn Association.

[8] Clark, M. H., steven, c. M., \& Daniel, n., Lauren K. Z. (2014). Mediating relationships between academic motivation, academic integration and academic performance. Learning and Individual Differences, 33, 30-38.

[9] Feldman, D. B., Rand, K. L., \& Kahle-Wrobleski, K. (2009). Hope and goal attainment: Testing a basic prediction of hope theory. Journal of Social and Clinical Psychology, 28, 479-497.

[10] Zhou, m. M., \& Kam, c. (2016): Hope and general selfefficacy: Two measures of the same construct?, The Journal of Psychology, 0 (0), 1-17.

[11] Katharine, h. G., aleksandra, c.,\& Ruth, v. V., tiina, L., Nyla, R. B. (2016). Feeling Hopeful Inspires Support for Social Change. Political Psychology, 37 (1), 89-107.

[12] Mataroria, p. L., marcus, a. H.,\& Hussain, A., et al. (2017). Burnout, quality of life, motivation, and academic achievement among medical students: A person-oriented approach. Perspect Med Educ, 6, 108-114.

[13] Liao, H., Ferdenzi, A. C., \& Edlin, M. (2012). Motivation, self-regulated learning efficacy, and academic achievement among international and domestic students at an urban community college: A comparison. Community College Enterprise, 18, 9-38. 
[14] Story, P. A., Hart, J. W., Stasson, M. F., \& Mahoney, J. M. (2009). Using a two-factor theory of achievement motivation to examine performance-based outcomes and self-regulatory processes. Personality and Individual Differences, 46, 391395 .

[15] McClelland, D. C. (1961). The achieving society. New York, NY: Free Press.

[16] Mehmet, a. K., \&Joshua, C. W. (2017). Examining associations among achievementmotivation, locus of control, academic stress, and life satisfaction: A comparison of U.S and international undergraduate students. Personality and Individual Differences, 111, 106-110.

[17] Li, y., lan, j.,\& Ju, c. (2015). Achievement motivation and attributional style as mediators between perfectionism and subjective well-being in Chinese university students. Personality and Individual Differences, 79, 146-151.

[18] Ahmad, I., \& Rana, S. (2012). Affectivity, achievement motivation, and academic performance in college students. Pakistan Journal of Psychological Research, 27, 107-120.

[19] Martinez, P. (2001). Improving student retention and achievement: What do we know and what do we need to find out? London: Learning and Skills Development Agency, 1-16 (Retrieved from)

[20] Bandura, A. (1982). Self-efficacy mechanism in human agency. American Psychologist, 37 (2), 122-147.

[21] Bandura, A. (1977). Self-efficacy: Toward a unifying theory of behavioral change. Psychological Review, 84 (2), 191-215.

[22] Liu, 1. Q.,\& Cheng, 1. S. (2017). The mediating effect of self-identity in the relationship between self-efficacy and achievement motivation of university students. China Journal of Health Psychology, 25 (4), 543-546.

[23] Andrew, j. M.,\& Katharine, s. (2017). The role of puberty in students' academic motivation and achievement. Learning and Individual Differences, 53, 37-46.

[24] Gannouni, k.,\& Ramboarison-Lalao, 1. (2016): Leadership and students' academic success: mediating effects of self-efficacy and self-determination, international Journal of Leadership in Education, 3-14.

[25] Multon, K. D., Brown, S. D., \& Lent, R. W. (1991). Relation of self-efficacy beliefs to academic outcomes: A meta-analytic investigation. Journal of Counseling Psychology, 38 (1), 3038 .

[26] Stajkovic, A. D., \&Luthans, f. (1998). Self-efficacy and work-related performance: A meta-analysis. Psychological Bulletin, 124 (2), 240-261.

[27] Cuevas, c., wolff, k. T.,\&Baglivio, m. T. (2017). Self-efficacy, aspirations, and residential placement outcomes: Why belief in a prosocial self matters. Journal of Criminal Justice, 52, 1-11.

[28] Schunk, D. H. (1995). Self-efficacy and education and instruction. In Maddux, J. E. (Ed.). Self-efficacy, adaptation, and adjustment: theory, research and application. 281-303. New York, NY: Plenum.

[29] Pajares, F. (1997). Current directions in self-efficacy research. In M. Maehr \& P. R. Pintrich (Eds.), Advances in motivation and achievement, 10, 1-49. Greenwich, CT: JAI Press
[30] Pajares, F. (1996). Self-efficacy beliefs in achievement settings. Review of Educational Research, 66, 543-578.

[31] Khalkhali, v., Aryanpour, h. R. (2013). Comparing the academic self-efficacy in students with entity and incremental intelligence theory. Education Science and Psychology, 1 (23), $10-14$.

[32] Snyder, C. R., Ilardi, S. S., Michael, S. T., \& Cheavens, J. (2000). Hope theory: Updating a common process for psychological change. In C. R. Snyder \& R. E. Ingram (Eds.), Handbook of psychological change: Psychotherapy processes and practices for the 21st century, 128-153. New York, NY: Wiley.

[33] Snyder, C. R. (2002). Target article: Hope theory: Rainbows in the mind. Psychological Inquiry, 13, 249-275. doi:10.1207/S15327965PLI1304_01.

[34] Snyder, c. R. (2005). Measuring hope in children what do children need to flourish? Springer, 61-73.

[35] Ling, y., e. Scott Huebner,\&Fu, p., zeng, y., he, y. (2016). a person-oriented analysis of hope in Chinese adolescents. Personality and Individual Differences, 101, 446-450.

[36] Rose, s., elkis-Abuhoff, D., goldblatt, R., \& Miller, E. (2012). Hope against the rain: Investigating the psychometric overlap between an objective and projective measure of hope in a medical student sample. The Arts in Psychotherapy, 39 (4), 272-278.

[37] Snyder, c. R., sympson, s. C., Ybasco, F. C., borders, t. F., Babyak, m. a., \& Higgins, r. L. (1996). Development and validation of the State Hope Scale. Journal of Personality and Social Psychology, 70(2), 321.

[38] Snyder, C. R., Harris, C., Anderson, J. R., Holleran, S. A., Irving, L. M., Sigmon, S. T., \& Harney, p. (1991). The will and theways: Development and validation of an individual-differences measure of hope. Journal of Personality and Social Psychology, 60(4), 570.

[39] Valle, M. F., Huebner, E. S., \& Suldo, S. M. (2006). An analysis of hope as a psychological strength. Journal of School Psychology, 44 (5), 393-406.

[40] Li, x. (2013). The intervention strategies of self-identity danger for the students in vocational school. Chinese Journal of Professional and Educational research, 32, 336-337.

[41] Li, y., lou, w. (2009). The reliability and validity test in adolescents' samples for the Self-identity scale. China Journal of Health Psychology, 17 (2), 181-182.

[42] Wang, c., hu, z. \&Liu, y. (2001). The study of reliability and validity for general Self-efficacy scale. Chinese Journal of Applied psychology, 7 (1), 37-40.

[43] Chen, c., shen, h. \& Li, x. (2009). Reliability and Validity of Adult Dispositional Hope Scale. Chinese Journal of Clinical Psychology, 17 (1), 24-26.

[44] Allison, P. D. (2003). Missing data: Quantitative applications in the social sciences. British Journal of Mathematical \& Statistical Psychology, 55, 193-196.

[45] Curran, p. J., west, s. G., \& Finch, j. F. (1996). The robustness of test statistics to normality and specification error in confirmatory factor analysis. Psychological Methods, 1 (1), $16-29$. 
[46] Muthe'n, B., \& Kaplan, D. (1992). A comparison of some methodologies for the factor analysis of normal Likert variables: A note on the size of the model. British Journal of Mathematical and Statistical Psychology, 45 (1), 19-30. Personality and Individual Differences, 38, 143-1473.

[47] Richard, b. D., lydia L. F., \& Jeffrey, j. M. (2015). achievement Goal Theory: The Relationship of Accounting Students' Goal Orientations with Self-efficacy, Anxiety, and Achievement, Accounting Education, 24 (2), 152-174.

[48] Zhang, j. \& Li, d. (2016). College students' professional identity and its relationship with achievement motivation and learning satisfaction. China Journal of Health Psychology, 24 (4), 562-565.

[49] Yang, d., liang, s., wu, h. (2016). The relationship between college students' achievement motivation and learning burnout:hope as a mediator. China Journal of Health Psychology, 24 (2), 255-259.

[50] Cole, D. a., Martin, J. M., Peeke, L. a., Seroczynski, A. D., \& Fier, j. (1999). Children's overand underestimation of academic competence: A longitudinal study of gender differences, depression and anxiety. Child Development, 70, 459-473.

[51] Caprara, g. V., Vecchione, m., alessandri, g., gerbino, m.,\&Barbaranelli, C. (2011). The contribution of personality traits and self-efficacy beliefs to academic achievement:A longitudinal study. British Journal of Educational Psychology, $81,78-96$.

[52] Zimmerman, B. J., \& Schunk, D. H. (2004). Self-regulating intellectual processes and outcomes: A social cognitive perspective. In D. Y. Dai, \& R. J. Sternberg (Eds.), Motivation, emotion, and cognition: Integrative perspectives on intellectual functioning and development (pp. 143-174). Mahwah, NJ: Lawrence Erlbaum.

[53] Salmela-Aro, K., \& Tynkkynen, L. (2010). Trajectories of life satisfaction across the transition to post-compulsory education Do adolescents follow different pathways?Journal of Youth and Adolescence, 39, 870-881.

[54] Duff, A., Boyle, E., Dunleavy, K., \& Ferguson, J. (2004). The relationship between personality, approach to learning and academic achievement. Personality and Individual Differences, $36,1907-1920$

[55] Savickas, M. L., Nota, L., Rossier, J., Dauwalder, J. P., Duarte, M. E., Guichard, J., van Vianen, A. E. (2009). Life designing: A paradigm for career construction in the $21 \mathrm{st}$ century. Journal of Vocational Behavior, 75, 239-250.

[56] Pintrich, P. R., \& Schunk, D. H. (2002). Motivation in education: Theory, research, and applications (2nd ed.). Upper Saddle River, NJ: Merrill.

[57] Maria, c. G., teresa, M. S., lea, f.,\&Laura, n., sara, s., salvatore, s. (2017). Visions about future: a new scale assessing optimism, pessimism, and hope in adolescents. Int J Educ Vocat Guidance, 17, 187-210.

[58] Benyamini, Y. (2005). Can high optimism and high pessimism co-exist? Findings from arthritis patients coping with pain.

[59] Sun, m.. (1998). Erik Erikson. identity:adolescents and dangerous [M]. Hangzhou, published by Education in Zhejiang, china. 